\title{
Rational placement of measuring systems in high dams
}

\author{
Georgy Shainyan ${ }^{1, *}$ \\ ${ }^{1}$ Candidate of technical Sciences, 26 Yaroslavskoe shosse, Moscow, 129337, Russia
}

\begin{abstract}
To solve the problem of rational placement of measuring systems in concrete dams, the experience of full-scale observations of horizontal displacements and stresses in the body of the arch dam of Inguri HPP (Georgia) was used with the use of statistical processing of the results of observations and the Barlow-Hunter-Proshan mathematical model. The type of the law of distribution of horizontal displacements and arch stresses was established by analyzing the histograms of these measured indicators of the static state of the structure. It is established that the change of horizontal displacements along the dam height is well described by the one-sided normal distribution law, and the arch stresses in the controlled alignment by the normal distribution law. The laws of distribution of random variables are established. Using the Barlow-Hunter-Proshan mathematical model enabled the use of economic criteria on the basis of the frequency characteristics of the indicators of trouble-free operation of the construction and obtain the recurrence relation for the sequence of coordinate points of the measuring systems. The results of calculations of the coordinates of the recommended location of straight plumb lines in the center console and tensometric rosettes in the measuring range of the Ingur dam at the level of $210 \mathrm{~m}$ for a rational placement scheme are presented. The calculation showed that the number of measuring systems installed in the body of the Ingur dam exceeds the optimum value.
\end{abstract}

\section{Introduction}

The design and construction of high hydropower facilities is closely related to in-situ observations and studies of their condition and operation, which are the most reliable and effective means of verifying the reliability of calculation methods and design decisions. Fullscale studies allow monitoring the work of structures in the construction and operational periods, timely identify deviations from the permissible indicators of the state of the structure, prevent incidents and accidents on dams. According to the results of field observations and studies during the construction and operation of dams, to monitor their condition with the help of measurement systems, laboratory tests and calculation methods, can be developed common methods of equipping facilities devices on a single principle. The developed methods can be effectively used in the design of newly constructed hydraulic structures in the section on the placement of measuring systems designed to measure horizontal and

\footnotetext{
* Corresponding author: SOTAE@mgsu.ru
} 
vertical movements, stress-strain state, temperature, opening of construction and structural joints, filtration in the body and the base of the dam. Currently, there is quite a lot of experience in the development and application of methods of field research. Devices of a new type for measuring displacements, stresses in concrete, filtration costs, piezometric levels have been developed. Automated systems for monitoring the behavior of hydraulic structures during the construction, filling of the reservoir and operation have been installed. Modern satellite systems "GLONASS" and GPS are used.

The research was carried out on the arch dam of Inguri HPP with the help of 2177 measuring systems, 46 of which are straight and reverse plumb lines. The body of the dam has three straight plumb lines and one in the rocky abutments of the banks. The displacements relative to the plumb lines were measured by an optical coordinator. Issues science-based task performances, the organization and conduct of field studies of hydraulic structures and their reliability was conducted by the staff of the field expedition on the construction of the Inguri hydroelectric power station of the Institute GruzNIIEGS and expedition of Tbilisi office of the Institute "Hydroproject".

The technique of rational placement of straight plumb lines in concrete dams with the use of statistical methods of analysis and mathematical model of Barlow-Hunter-Proshan, based on the modern experience of field observations and research. The type of the law of distribution of horizontal displacements of the dam is established by analyzing the histograms of the measured indicators of the static state of the structure. The required number of plumb lines for the key console of the Ingur arch dam has been specified. In practice, this technique was used in the design of high concrete dams.

Many years of experience in the research and operation of the arch dam Ingur HPP, allowed to assess compliance with the established requirements of special control and to allocate the necessary amount for monitoring the strength and stability of the structure. The proposed methods of data analysis of field studies based on the theories of probability, statistics and reliability were used in the design of the dam Hudoni HPP (Georgia).

\section{Introduction}

When developing a project for the construction of hydraulic structures, a section of field observations is provided [1-3]. For the first time in the world, full-scale observations were put on a scientific basis for the construction of the Nizhne-Svirskaya HPP. As a result of regular observations of geodetic methods for the construction was proved the possibility of the construction of such dams on compressible soils, ensured their flawless construction and operation.

The first experience of full-scale observations showed the need for highly qualified conducting them at the facilities under construction and equipping the latter with measuring systems. On a fundamentally new basis set of national science in the area of field research, the scientists of JSC "Institute Hydroproject", VNIIG, GruzNIIEGS [4-6]. In the world practice on hydraulic structures these engineering security systems began to be introduced from the end of 80-ies of the last century. This was largely due to the actualization of the issue of dam safety in the activities of the international Commission on large dams (ICOLDInternational Commission of Lage Dams). The acceleration of development was the international Symposium on new trends and methodological recommendations on security held in Barcelona in July 1998 [7]. In the reports of the VI International scientific conference, held in November 2018 in Moscow in MISI-MGSU, much attention was paid to the necessity of equipping with modern measuring systems for monitoring the behavior of hydraulic structures from loads and external influences. For this purpose, a monitoring system (MSMonitoring System) was developed. It is a group of physical tools, combined into a system to determine the main controlled parameters of the technical condition of the structure such 
as precipitation, planned displacement and slopes, filtration parameters, deformation, stress and temperature [4]. The experience of observing the overall deformation of the high dam: Ingur (Guziya), Vajont (Italy), Mauvoisin (Switzerland), Kurobe 4 (Japan), Chirkey (Russia), Sayano-Shushenskaya (Russia), Hoover (USA), Shoebuy (China) allows you to accurately and reliably estimate the static behaviour of the structure during reservoir filling and during operation [8-10].

Placement of measuring systems in concrete dams is determined by their type, size and topographical indicators of the target (fig. 1) [11]. Horizontal movements of arch dams allow to study the behavior of the structure throughout its height. They are observed by means of plumb lines, which are installed in the key section and in sections with maximum deflections [12]. Due to the design features of high dams it is not always possible to install plumb lines on one line. Therefore, they are arranged in groups in vertical sections, passing through the observation galleries and galleries with a step of 30-50 m (fig. 2). According to these groups of plumb lines, the horizontal movements of the consoles are recorded and the corresponding plots are plotted. The choice of this step is determined by the experience of the designer and is largely volitional.

\section{Materials and methods}

The studies were carried out on the arch dam of Ingur hydroelectric power station (Georgia), the height of which is $271.5 \mathrm{~m}$, the crest length is $758 \mathrm{~m}$, including the abutments of $118 \mathrm{~m}$, the thickness in the key section on the crest of $10 \mathrm{~m}$, at the mark of the perimeter seam of $50 \mathrm{~m}$ and at the contact of the dam with the base of $90 \mathrm{~m}$. the Ratio of the length of the dam along the crest to its height is 2.3 ; the coefficient of harmony is 0.228 . The body of the dam has a double curvature and is cut into 39 sections by helicoidal cross-sectional seams, normal in any horizontal section to the axis of the corresponding arch and is equipped with 46 straight and reverse plumb lines. This is the Central console of section 18 and the console with maximum deflections: sections 7, 12, 26, 32 (Fig. 2). The planned dimensions of the average design block of concreting, where the strain gauge sockets are placed $30 \times 17 \mathrm{~m}$, the height of the blocks is 0.75 and $1.5 \mathrm{~m} \mathrm{[2].}$

Deformation at the Enguri arch dam was carried out according to the program drawn up NIS Hydroproject and Graniies with mortgages transducers of linear displacement of the string type. From the group of these converters located along the coordinate axes and at an angle of 450, strain-gauge sockets with an unstrained sample in the "shrink cone" were performed, which were placed on the grid in the amount of 654 units, where the vertical measuring valves are located in sections: $2,4,12,18,26,32,37,39$, horizontal - on marks: in a stopper - 201 and $222 \mathrm{~m}$, and in arch part - 261, 293, 343, 393 and $435 \mathrm{~m}$. Measuring systems are grouped into 100 strain gauge sockets of the "fan" type in the pilot sections at the level of the valves (Fig. 2). Measuring points are placed along the thickness of the dam as follows: in the key section - six, and in the remaining sections - four. Above $369 \mathrm{~m}$, where the dam was built without a longitudinal seam, the number of measuring points was reduced to three. The extreme measuring points in the sections are spaced from the dam faces at a distance of $1 \mathrm{~m}$ to exclude the influence of daily fluctuations in air temperature on the readings. The number and place of installation of strain gages, appointed on the basis of theoretical and model studies. Rational placement of measuring systems in dams with their minimum number causes a decrease in the cost of field observations and at the same time provides maximum information about the static state of the structure [3]. All measuring points at the bottom face are equipped with flat strain gauge sockets of four, and at the pressure face of five linear displacement transducers. solving the problems of rational placement of measuring systems on the dam used statistical methods of analysis of the results of field studies, diagnosis and reliability [13-16]. 


\section{Results}

Observations have shown that horizontal displacements are natural, associated with an increase in pressure and temperature change. The maximum radial displacements on the crest of the key section reached 54-56 mm, in the quarters of the arch 41-48 mm. the Seasonal scale of the deflections of the crest is $26 \mathrm{~mm}$.

The main factor determining changes in horizontal displacements is the change in hydrostatic load. The temperature leaving is most noticeable at the crest of the dam, where the scope of its oscillations is greater than the component from the change in pressure.

To solve the problem of rational placement of plumb lines, the experience of observing the movements of the Ingur arch dam and the statistical method of analysis using the mathematical model of Barlow-Hunter-Proshan were applied. According to the testimony of pitches (Fig. 2) recorded the frequency of changes in horizontal movements of the key console by at least $2 \mathrm{~mm}$ over a three-year period and reduced to table 1 on the basis of the distance from the level of $240 \mathrm{~m}$ to the base of the dam.

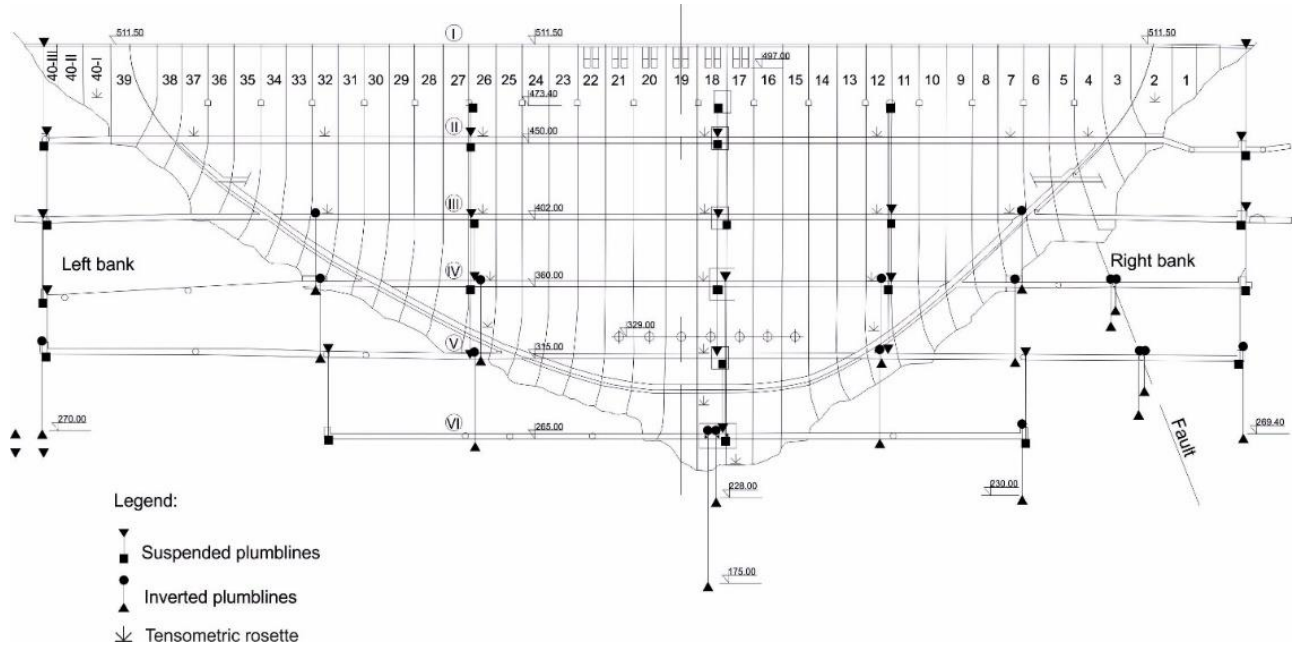

Fig. 1. The location of the measurement systems on the arched dam the Inguri dam 


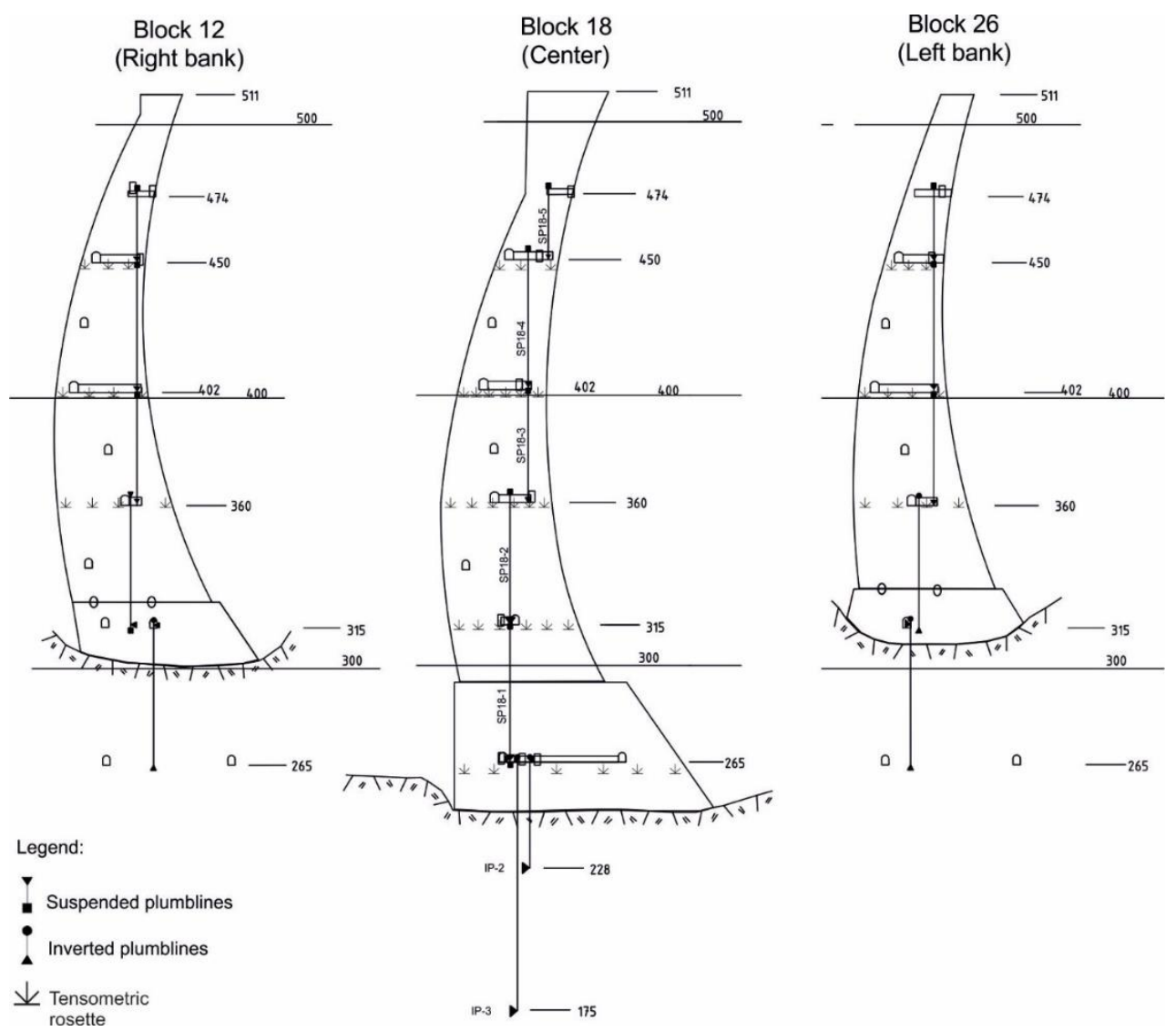

Fig. 2. The layout of the measurement systems in sections of the arch dam of the Inguri dam

Table. 1. Frequency change of horizontal displacements key console

\begin{tabular}{|c|c|c|c|}
\hline $\begin{array}{c}\text { Plumb design } \\
\text { number }\end{array}$ & Level, m & $\begin{array}{c}\text { Absolute frequency } \\
\text { of displacement } \\
\text { measurement, } \\
\boldsymbol{n}_{\boldsymbol{k}}\end{array}$ & $\begin{array}{l}\text { The current } \\
\text { coordinate of the } \\
\text { console, } \mathbf{m} \\
\boldsymbol{L}_{\boldsymbol{k}}\end{array}$ \\
\hline $18 \mathrm{SP}-5$ & 240 & 157 & 0 \\
\hline $18 \mathrm{SP}-4$ & 210 & 159 & 30 \\
\hline $18 \mathrm{SP}-3$ & 162 & 138 & 48 \\
\hline $18 \mathrm{SP}-2$ & 120 & 96 & 42 \\
\hline $18 \mathrm{SP}-1$ & 75 & 49 & 55 \\
\hline IP-2 & 25 & 10 & 50 \\
\hline
\end{tabular}

After that, the corresponding frequency distribution curves (experimental and theoretical) of the measurement results were constructed, for which the frequencies of changes in horizontal displacements in areas of ten-meter length were determined

$$
v_{k}=\frac{n_{k}}{0.1 * L_{k}} \quad(k=1, N ; N=6),
$$


where $n_{k}$ - is the absolute frequency of measuring movements; $L_{k}-$ is the current coordinate of the console, measured from the level of $240 \mathrm{~m}$.

Then experimental relative frequencies were established at the same sites

$$
P_{k}=\frac{v_{k}}{\sum_{i=1}^{N} v_{i}}
$$

The variance was found by the formula

$$
\sigma=\sqrt{\sum_{j=1}^{N} P_{j} \tilde{L}_{j}^{2}}
$$

where $P_{j}$ is the relative frequency measurement;

$L_{j}$-coordinate of the middle of the j-th section $-\tilde{L}_{j}=\frac{1}{2}\left(L_{j}+L_{j+1}\right)$.

According to the calculations, the frequency curve of the experimental distribution of displacement jumps was constructed and compared with the curve of the one-sided normal distribution law [3-5]. The curve of the one-sided normal distribution law can be represented by the distribution density formula:

$$
f\left(\tilde{L}_{j}\right)=\sqrt{\frac{2}{\pi \sigma^{2}}} e^{-\frac{\widetilde{L}_{j}^{2}}{2 \sigma^{2}}}
$$

Knowing the values of $\widetilde{L}_{j}$ and $\sigma$, we calculated the distribution density $f\left(\widetilde{L}_{j}\right)$, and then from the ratio

$$
\tilde{P}_{j}=\frac{f\left(\tilde{L}_{j}\right)}{\sum_{j=1}^{N} f\left(\tilde{L}_{j}\right)}
$$

$P_{j}$ - theoretical relative frequency jumps of displacements.

Thus obtained theoretical $P_{j}$ and experimental $\tilde{P}_{j}$ relative frequencies for jumps of horizontal displacements, expressed as a percentage, are given in table 2.

Table. 2. Frequency of jumps of horizontal movements

\begin{tabular}{|c|c|c|c|c|c|c|}
\hline$P_{j}, \%$ & 8.6 & 5.4 & 5.3 & 3.5 & 1.6 & 0.6 \\
\hline$\tilde{P}_{j}, \%$ & 7.4 & 6.6 & 5.1 & 3.5 & 1.6 & 0.75 \\
\hline
\end{tabular}

On the ordinate axis relative frequencies of jumps of displacements in percent were postponed, and on the abscissa axis-distances $L_{j}$ in meters and using the data given above were plotted points of experimental (---) and theoretical (-) frequency curve (Fig. 3). The constructed curves clearly show the proximity of the experimental and theoretical frequency characteristics for the jumps of displacements. 


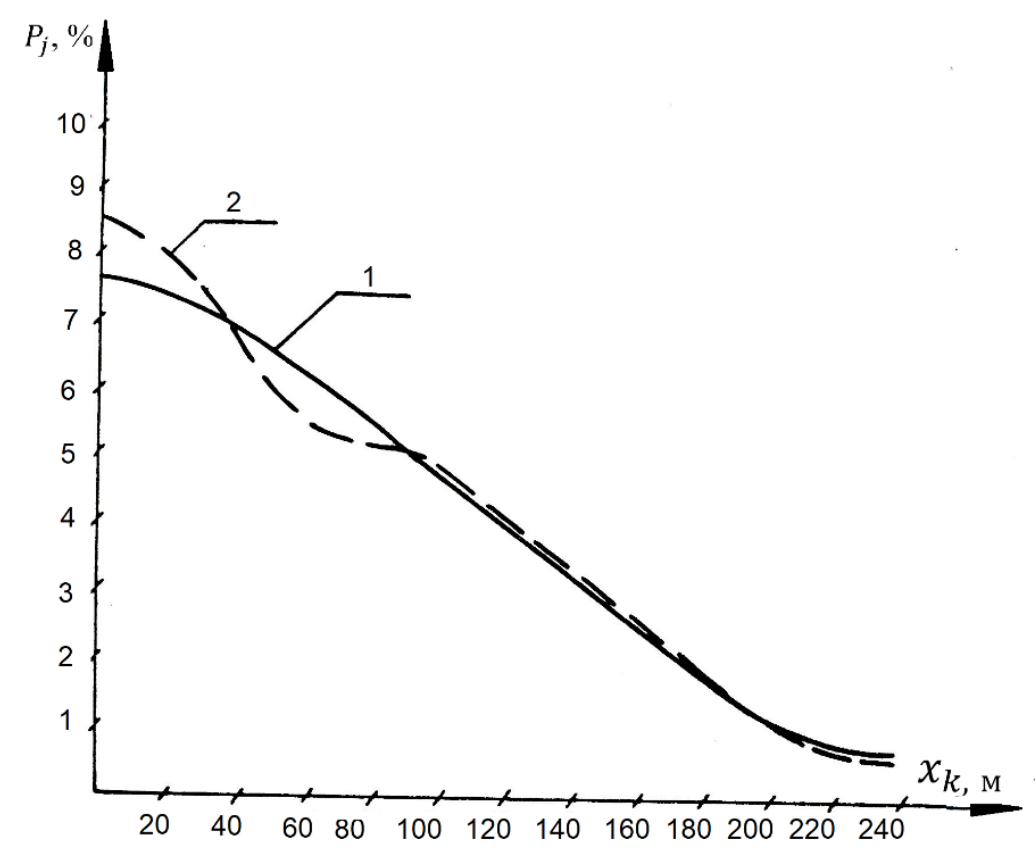

Fig. 3. Theoretical (1) and experimental (2) distribution curves of the measured horizontal displacements of the key console.

Thus, the frequency of jumps of horizontal displacements along the height of the dam can be approximated by a one-sided distribution law. Now that the distribution law is established, it is possible to solve the problem of rational placement of plumb lines in the structure. The mathematical model of Barlow-Hunter-Proshan allows to use the economic criterion on the basis of frequency characteristics of accident-free operation of the structure and to obtain recurrence relations for the sequence of vertical coordinates of plumb lines fixing their placement:

$$
x_{k+1}=x_{k}+\frac{F\left(x_{k}\right)-F\left(x_{k-1}\right)}{f\left(x_{k}\right)}-\frac{C_{1}}{C_{2}},
$$

where $C_{1}$-cost of installation of one measuring system (plumb);

$C_{2}$-the cost of failure detection of the dam, which falls on $1 \mathrm{~m}$ of running length;

$F(x)$-distribution function of dam failure-free operation; $f(x)$ - the probability of failure-free operation of the dam, obtained by interpolating the frequency histogram of horizontal displacement measurement; $x_{k}$-current coordinate of the placement of the pitches.

The practical use of formula (6) presupposes a preliminary selection of $x_{0}$ and $x_{1}$ coordinates based on physical considerations. The sequence $x_{k}$ is defined recursively $\frac{C_{1}}{C_{2}} \approx 0$, since $C_{1} \ll C_{2}$. Since the probability density is sufficiently $f(x)$ well interpolated by the onesided normal distribution law, the function $F(x)$ can be expressed in terms of the Laplace function $\Phi(x)$. Taking $\frac{C_{1}}{C_{2}} \approx 0$, the formula (6) after mathematical transformations write as

$$
x_{k+1}=x_{k}+\frac{\sigma}{2}+\frac{\Phi\left(z_{k}\right)-\Phi\left(z_{k-1}\right)}{f\left(y_{k}\right)}
$$

where $y_{k}=\frac{x_{k}}{\sigma}$ and $z_{k}=\frac{y_{k}}{\sqrt{2}}$. 
As already noted, two initial conditions are necessary for the use of the recurrent formula (6). As these conditions, we set the coordinates $x_{0}$ and $x_{1} . x_{0}=0$, and $x_{1}$ choose at first arbitrarily; finally, let's stop at the value $x_{1}$, at which the "function" $\Delta x(k)$, quickly becomes stationary (that is, it ceases to depend on $k$ ).

For fig. 4 shows a family of curves $\Delta x(k)$, defined by $x_{1}$.

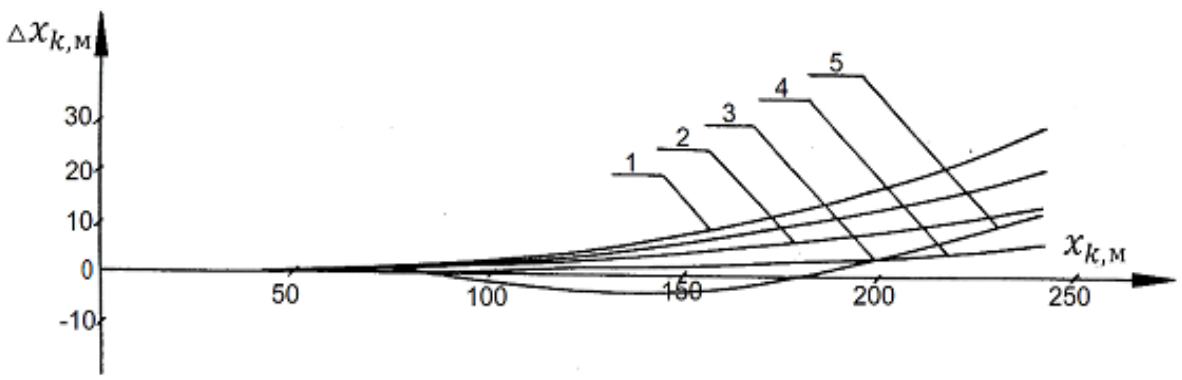

Fig. 4. Graphs of the dependence of the rational placement of plumb lines for different values of $x_{k}: 1-x_{1}=65 \mathrm{~m} ; 2-x_{2}=60 \mathrm{~m} ; 3-x_{3}=55 \mathrm{~m} ; 4-x_{4}=50 \mathrm{~m} ; 5-x_{5}=$ $45 \mathrm{~m}$

$x_{1}=50 \mathrm{~m}$.

This value was used in the formula (7), with which table 3 was compiled. This table summarizes the results of calculations of the rational placement of plumb lines in the key console of the arch dam.

Table. 3. Straight plumb lines in the key console at a rational location

\begin{tabular}{|c|c|c|c|c|c|c|}
\hline $\begin{array}{c}\text { Console } \\
\text { section }\end{array}$ & $x_{k}, \mathrm{~m}$ & $y_{k}$ & $z_{k}$ & $f\left(y_{k}\right)$ & $\Phi\left(z_{k}\right)$ & $L_{k}=x_{k+1}-x_{k}$ \\
\hline 1 & 50.0 & 0.46 & 0.33 & 0.38 & 0.37 & 51.8 \\
\hline 2 & 101.8 & 0.95 & 0.67 & 0.29 & 0.67 & 56.0 \\
\hline 3 & 157.8 & 1.42 & 1.01 & 0.15 & 0.84 & 60.8 \\
\hline 4 & 218.6 & & & & & \\
\hline
\end{tabular}

If we move from the $x_{k}$ coordinates to the levels, we get that the straight plumb lines in the body of the dam should be located at the levels: 24, 190, 138.2 and $11.4 \mathrm{~m}$. in Total, we need 4 plumb lines, that is, one less than in the key console. It should be clarified that the reverse plumb, relative to which observations are made, is installed in the well at a depth of $50 \mathrm{~m}$. The number and place of installation of strain gauges, designed to monitor the stressstrain state of the dam, appointed on the basis of theoretical and model studies.

Rational placement of measuring systems in dams with their minimum number causes a decrease in the cost of field observations and at the same time provides maximum information about the static state of the structure.

We analyze the placement of strain gages installed at a distance of $1 \mathrm{~m}$ from the upper face of the Ingur dam arch at the level of $203 \mathrm{~m}$ (Fig.5) in sections 4, 7, 12, 18, 26, 32, 37 and remote from the starboard side of the dam respectively on 25,$8 ; 77,0 ; 162,3 ; 262,6 ; 395,5$; 497,$6 ; 583,2 \mathrm{~m}$ with a total length of the arch $626.5 \mathrm{~m}$. 


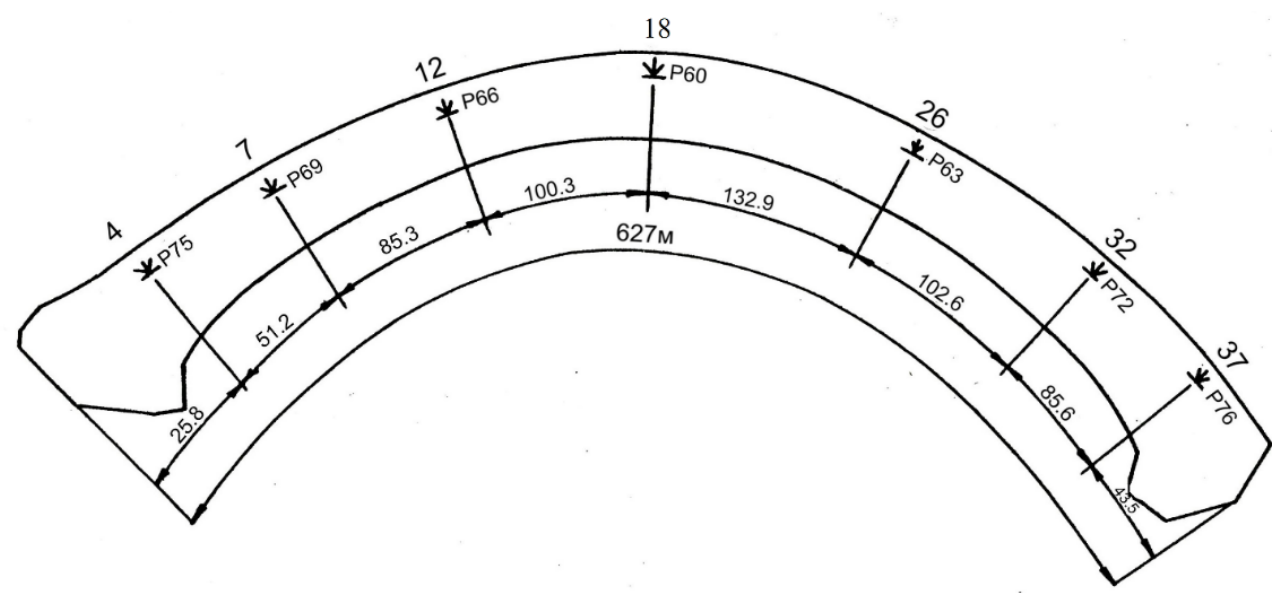

Fig. 5. The scheme of placement of strain gauge sockets in the horizontal section of the arch dam at the level of $203 \mathrm{~m}$.

We determine at the beginning of the frequency characteristics of the changes in the arch voltage of not less than $0.5 \mathrm{MPa}$ from the readings of strain gage sockets P № 75, 69, $66,60,63,72,78$ for five years.

Next, we construct experimental and theoretical curves of the distribution of changes in the arched stresses and determine their frequency characteristics. Set the relative experimental frequency of the voltage change from the expression:

$$
v_{i}=\frac{n_{i}}{\sum_{j=1}^{N} n_{j}},
$$

where $n_{j}$ is the frequency of changes of arch stresses on the sections;

$\mathrm{N}$-number of parcels.

The relative theoretical frequency of stress changes is calculated by the formula:

$$
\widetilde{\omega}(i)=\frac{\omega_{i}}{\sum_{j=1}^{n} \omega_{j}}
$$

where $\omega_{i}=\omega(x)$ - is the interpolation density of the distribution obeying the normal law:

$$
\omega(x)=\frac{1}{\sqrt{2 \pi} \sigma} e^{-\frac{(x-\bar{x})^{2}}{2 \sigma^{2}}},
$$

where $\bar{x}$ - is the expectation of a random variable;

$\sigma$ - is the standard deviation of the experimental and theoretical frequencies of the arch

\begin{tabular}{|c|c|c|c|c|c|c|}
\hline $\begin{array}{l}\text { Section of } \\
\text { the arch }\end{array}$ & Section & $\begin{array}{l}\text { \# strain } \\
\text { gauge } \\
\text { outlet }\end{array}$ & $\begin{array}{c}\text { Distance } \\
\text { from the } \\
\text { right Bank, } \\
\text { m }\end{array}$ & $n$ & $\sigma, \%$ & $\omega, \%$ \\
\hline 1 & 4 & 75 & 25.8 & 19 & 6.64 & 4.68 \\
\hline 2 & 7 & 69 & 77.0 & 21 & 7.34 & 12.55 \\
\hline
\end{tabular}
stresses are summarized in table 4.

Table. 4. Arch voltage frequencies 


\begin{tabular}{|c|c|c|c|c|c|c|}
\hline 3 & 12 & 66 & 162.3 & 65 & 22.72 & 12.55 \\
\hline 4 & 18 & 60 & 262.6 & 74 & 25.90 & 27.02 \\
\hline 5 & 26 & 63 & 395.5 & 50 & 17.48 & 21.48 \\
\hline 6 & 32 & 72 & 497.6 & 35 & 12.23 & 11.38 \\
\hline 7 & 37 & 78 & 583.2 & 22 & 7.69 & 0.32 \\
\hline
\end{tabular}

The graphical results of the experimental and theoretical curve calculations are shown in (fig. $6)$.

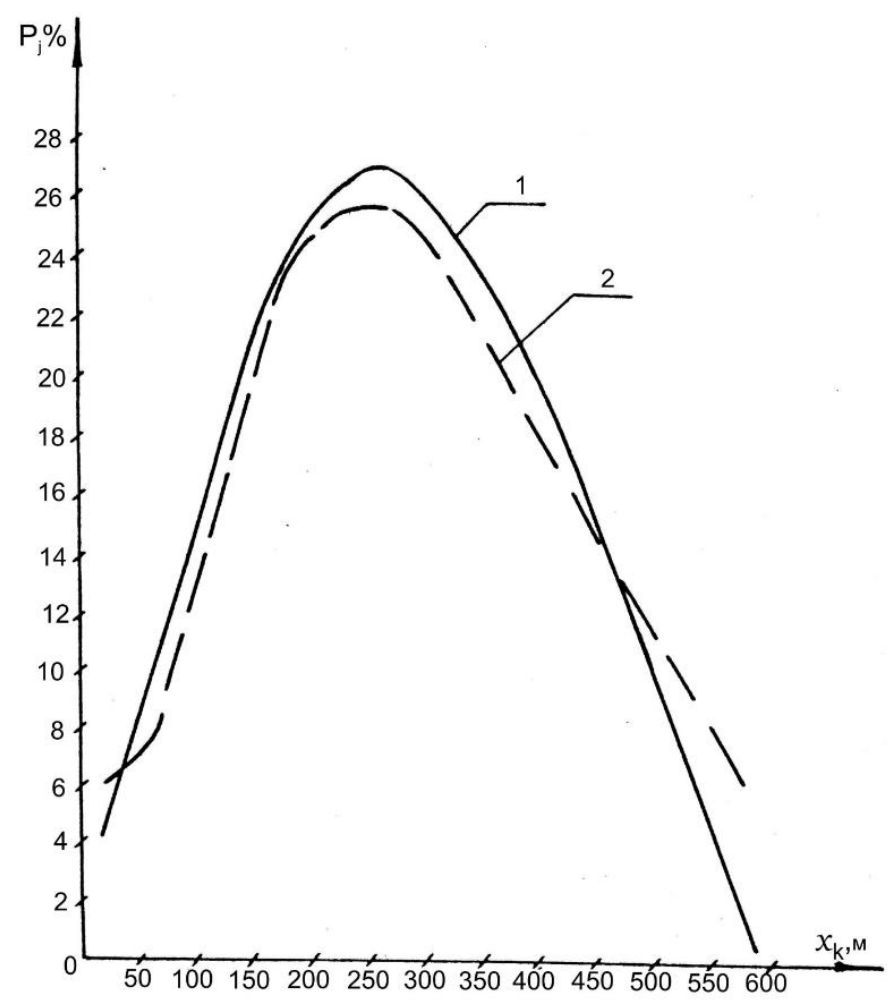

Fig. 6. Theoretical (1) and experimental (2) distribution curves of the results of the calculated arch stresses of the dam in the alignment at the level of $210 \mathrm{~m}$.

Despite the pointwise variance of the functions

$v(i)$ and $\omega(i)$ their integral characteristics, which Express the probabilities of different events, practically coincide.

Let's use the mathematical model (11)

$$
x_{k+1}=x_{k}+\frac{F(x)-F\left(x_{k-1}\right)}{f\left(x_{k}\right)}-\frac{C_{1}}{C_{2}}
$$

Since the probability density $f(x)$ obeys the normal Gauss distribution law, the distribution function $F(x)$ can be expressed in terms of the Laplace function $\Phi(x)$ and, after probing the expression (11), give it the following form:

$$
x_{k+1}=x_{k}+\frac{\sigma}{2}+\frac{\Phi\left(z_{k}\right)-\Phi\left(z_{k-1}\right)}{f\left(y_{k}\right)}-\frac{C_{1}}{C_{2}}
$$


where $y_{k}=\frac{x_{k}-\bar{x}}{\sigma} ; \quad z_{k}=\frac{y_{k}}{\sigma \sqrt{2}} ; \quad \sigma=\sqrt{\frac{\sum_{i=1}^{N}\left(x_{i}-\bar{x}\right)^{2}}{N-1}} ; \quad \frac{C_{1}}{C_{2}} \approx 0 ; N$ - is the number of parcels.

Selecting sequentially the values of the $x_{k}=120,115,110,105,100 \mathrm{~m}$, satisfying the mathematical model (12) with $\mathrm{x}_{0}=0$, with recursive procedures define the respective roles and build curves.

From the family of curves shown in (fig.7), choose the one that has the most stationary character. This curve will be the one whose functions are obtained at $x_{1}=105 \mathrm{~m}$.

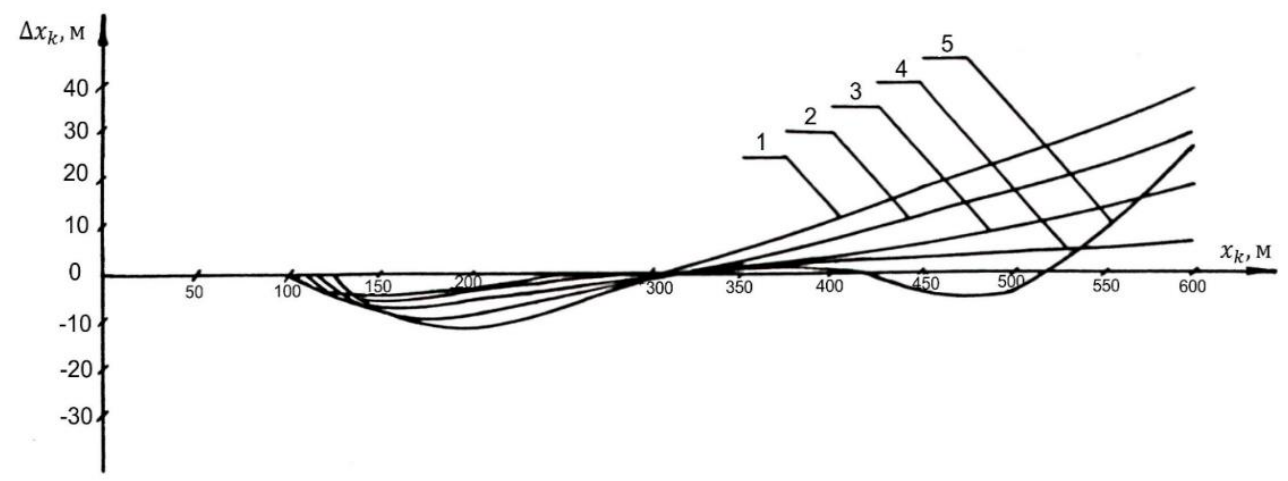

Fig. 7. The graphs of rational accommodation of strain gauge rosettes for various values of $x_{k}: 1-x_{1}=120 \mathrm{~m} ; 2-x_{2}=115 \mathrm{~m} ; 3-x_{3}=110 \mathrm{~m} ; x_{4}=105 \mathrm{~m} ; x_{5}=100 \mathrm{~m}$;

The results of calculations of rational placement of strain gauges in the measuring section of the dam at the level of $203 \mathrm{~m}$ are summarized in table 5 .

Table. 5. The location of strain gauge rosettes in the pack of the dam at elevation $203 \mathrm{~m}$

\begin{tabular}{|c|c|c|c|c|c|c|}
\hline $\begin{array}{c}\text { Section } \\
\text { of the } \\
\text { arch }\end{array}$ & $\boldsymbol{x}_{\boldsymbol{k}}, \mathbf{m}$ & $\boldsymbol{y}_{\boldsymbol{k}}$ & $\boldsymbol{z}_{\boldsymbol{k}}$ & $\boldsymbol{f}\left(\boldsymbol{y}_{\boldsymbol{k}}\right)$ & $\boldsymbol{\Phi}\left(\mathbf{z}_{\boldsymbol{k}}\right)$ & $\begin{array}{l}\boldsymbol{L}_{\boldsymbol{k}} \\
=\boldsymbol{x}_{\boldsymbol{k}+\mathbf{1}}-\boldsymbol{x}_{\boldsymbol{k}}\end{array}$ \\
\hline 1 & 105.0 & -0.85 & $-0,60$ & -0.28 & -0.60 & \\
\hline 2 & 188,7 & -0.46 & -0.32 & -0.36 & -0.33 & 83.7 \\
\hline 3 & 268.7 & $-0,08$ & -0.06 & -0.40 & -0.05 & 80.0 \\
\hline 4 & 343,3 & 0,27 & 0,19 & 0.38 & 0.22 & 74.6 \\
\hline 5 & 419,0 & 0,62 & 0.44 & 0.33 & 0.47 & 75.7 \\
\hline 6 & 499.8 & & & & & 80.8 \\
\hline
\end{tabular}

From this table it follows that the first strain gauge outlet for the Ingur arch dam at the level of $203 \mathrm{~m}$, it would be more rational to place at a distance of $105 \mathrm{~m}$ from the right side of the dam, and the following-through 83,$7 ; 80,0 ; 74,6 ; 75,7 ; 80.8 \mathrm{~m}$, which corresponds to the sections $9,13,19,23,28,33$. Such placement of measuring systems in the body of structures would reduce their number in one section of the measuring section by 6 strain sockets with unstrained samples in the "shrinkage cone".

To assign a rational distance between the measuring systems, designed and newly built hydraulic structures, it is necessary to use the developed technique for laboratory models, which will simulate the load and impact. According to the variability of stresses in the dam model, the distribution laws are established, after which the optimal distances between the measuring systems are assigned using the Barlow-Hunter-Proshan mathematical model. 


\section{Discussion}

Through the execution of design solutions for equipment of Inguri arch dam measuring systems, field observations and theoretical studies of statistical analysis methods and mathematical models Barlow-Hunter-Proshin, a form of the distribution of horizontal displacements, for determining the number of pitches in the body of concrete dams. The distance between the strain Gauss sockets is determined by the normal Gauss distribution law and is expressed in terms of the Laplace function, which allows you to choose the sequence of their placement. The developed method can be used for rational placement and other types of measuring systems used to control the technical condition of structures [17-20]: opening of construction and structural joints, filtration in the body and the base of the dam, temperature conditions, deformation of structures.

On the basis of modern experience of field observations on the arch dam of the Ingur hydroelectric power station using the proposed effective method of rational placement of measuring systems on dams, recommendations were developed for the design organization to clarify the range and number of devices required for full coverage of trouble-free operation of the hydroelectric power plants under construction. The technique can be used in the preparation of the project of field observations and studies on concrete structures of various types.

\section{References}

1. Yu. P. Lyapichev, Design and construction of modern high dams: textbook. 275 p. (Moscow, RUDN, 2014)

2. A. Asnake, A. Cagiano, B. Ferraro, E. Zoppis, Managing unprecedented challenges at Gibe III dam, Ethiopia Water Storage \& Hydropower Development for Africa. pp. 5863 (2015)

3. C. M. Escobar, A. M. Posada, Recent experience on design, construction and performance of CFRD dams, 6 th International Conference on Case Histories in Geotechnical Engineering, pp. 1-9 (2008)

4. G. I. Chogovadze, I. M. mghebrishvili, I. E. Lomov, Enguri hydro power plant, 200 p. (Moscow, Energoatomizdat, 1987)

5. A. N. Marchuk, Some lessons of field observations on high concrete dams, Hydrotechnical construction, 4, pp 2-12 (2018)

6. I. K. Nonjew, G. A. Shahinyan, System engineering of safety of hydraulic structures. Proceedings of the VI International conference, pp. 217-220 (Moscow, MISI-MGSU Publishing house, 2018)

7. A.A. Balkema, Proceedinds of the International Simposium on New Trends and Guidelines on DamSafety, Vol. I and II, (Rotter-dam, Brookfield, 1998)

8. E. Y. Zateeva, The Experience of creating data banks to monitor the status of large HPP, Hydraulic engineering, 7, pp. 42-45 (2005)

9. Ye Zhu, Lu Lu, Nonlinear static analysis of Shuibuya dam in China - World's Highest CFRD, Electronic Journal of Geotechnical Engineering, 21, Bund 04, pp. 1527-1537 (2016)

10. P. Johannesson, S. L. Tohlang, Lessons learned from Mohale, International Water Power \& Dam Construction 59(8), pp.16-25 (2007) 
11. L. B. Wang, Q. Yan, Analyze on development prospects of 300m level ultra-high CFRD from Shuibuya high CFRD, Asia-Pacific Power and Energy Engineering Conference. (2010) DOI: 10.1109/appeec.2010.5448667

12. G. I. Kuznetsov, results of geodetic measurements on the Ingur arch dam under construction. Hydraulic engineering, 3, pp. 34-38 (1983)

13. L. Wen, J. Chai, Z. Xu, Y. Li, A statistical review of the behavior of concrete-face rockfil dams based on case histories, Geotechnique, 68(9), pp. 749-771 (2018) DDI: 10. 1007/s11431-007-6007-5.

14. V. E. Gurman, Guide to solving problems in probability theory and mathematical statistics, 400 p. (Moscow, Higher school, 1979)

15. P. Marques, N. L. S. De Pinto, CFRD dam characteristics learned from experience, International Journal on Hydropower and Dams, 12(1), pp. $72-76$ (2005)

16. M. Tatin, M. Briffaut, F. Dufour, A. Simon, J.-P. Fabre, Statistical modelling of thermal displacements for concrete dams: Influence of water temperature profile and dam thickness profile, Engineering Structures, 165, pp. 63-75 (2018) DOI: 10.1016/j.engstruct.2018.03.010.

17. M. Tatin, M. Briffaut, F. Dufour, A. Simon, J.-P. Fabre, Thermal displacements of concrete dams: Accounting for water temperature in statistical models, Engineering Structures, 91, pp. 26-39 2015 DOI: 10.1016/j.engstruct.2015.01.047.

18. V. I. Kaftan, A.V. Ustinov, application of global navigation satellite systems for monitoring deformations of hydraulic structures, Hydrotechnical construction, 12, pp. 11-19 (2012)

19. A. V. Ustinov, Technology of satellite geodetic monitoring of hydraulic structures. Hydrotechnical construction, 6, pp. 39-43 (2014)

20. A. V. Ustinov, V. I. Kaftan, Technology of monitoring the movements of hydraulic structures in the process of compensation injection, Hydraulic engineering, 1, pp. 2-7 (2019) 